\title{
Tekil Kazık ve Grup Kazıkların Oyulmaya Karşı Taban Koruma Sistemlerinin Nümerik Modelleme Yöntemiyle İncelenmesi
}

\author{
Kemal BAL ${ }^{1}$ iD, Mehmet DİKİĊ ${ }^{2}$ iD, Murat AKSEL $^{2 *}$ \\ ${ }^{\text {I} Y a z u b i ~ P r o g r a m l a m a ~ L t d . ~ S ̧ t i ., ~ I ̇ s t a n b u l, ~ T u ̈ r k i y e . ~}$ \\ kemalbal@bellenti.com \\ ${ }^{2}$ Alanya Alaaddin Keykubat Üniversite, Rafet Kayış Mühendislik Fakültesi,Inşaat Mühendisliği Bölümü, \\ Antalya, Türkiye. \\ *murat.aksel@alanya.edu.tr
}

\begin{abstract}
Özet
Su içine veya su üzerinden geçiş için yapılan yapılarda taşıyıcı sistem olarak kazıklar ve ayaklar kullanılmaktadır. Bu yapıların tasarımı sürecinde, akım ortamı ile etkileşimini doğru tarif edebilmek tasarımın doğruluğu açısında önem taşımaktadır. Yanlış tasarım sonrasında doğru uygulama olsa dahi yapının çevresel koşulların etkisi altındaki durumu doğru ön görülmediğinden yapılarda hasarlar meydana gelmektedir. Yanlış tasarım yapılarak projelendirilmiş kazık taşıyıcı sisteme sahip yapıların hasarı, bilhassa etrafında meydana gelecek oyulma paterni ve oyulma derinliği sebebiyle olasıdır. Yapısal hasarlar önemli ekonomik zararlara neden oldukları gibi ek olarak dolaylı zararlara da neden olurlar. Yapılan çalışmalarda ağır hasar gören veya yıkılan köprülerinde hasar nedenlerinin çoğu kazık çevresindeki oyulmalardan kaynaklandığı görülmektedir. Su içindeki yapı etrafındaki oyulma mekanizması su yapıları mühendisliğinde önemli bir çalışma alanıdır. Oyulmanın önlenebilmesi için kazık çevresinde ve kazık yakınındaki tabanda akım karakteri iyi bir şekilde anlaşılmalıdır. Bu çalışmada üç farklı kazık sistemi,(tekil, ikili ve üçlü grup) akıntı etkisi altında hesaplamalı akışkanlar dinamiği metodu kullanılarak OpenFOAM çözücüsü yardımıyla incelenmiştir. Yapılan çalışmalarda yapıların çevresindeki taban kayma gerilmesi değerleri hesaplanmış ve koruma yapısı olarak kullanılabilecek taş boyutları ve gerekli koruma alanı hesaplanmıştır. Çalışılan ortam şartları ve taşıyıcı yük kapasiteleri göz önüne alınarak incelendiğinde ikili kazık grubunun tekil kazık ve üçlü gruptan hidrodinamik anlamda daha verimli olduğu bulunmuştur. Çevresindeki $120 \mathrm{~m}^{2}$ lik bir alanda oyulma riski hesaplanmıştır.
\end{abstract}

Anahtar Kelimeler: Oyulma, koruma yapısı, OpenFOAM, hesaplamalı akışkanlar dinamiği

\section{Investigation of Scour Protection of Monopile and Group Piles Performance by UsingNumerical Modeling}

\section{Abstract}

In the design process of piled structures, it is important to accurately describe their interaction with the flow environment in terms of the accuracy of the design. Even if the correct application is applied after the wrong design, the structure under the influence of environmental conditions is not foreseen correctly, thus damaging the structures that occur. Structural damage causes significant economic losses as well as indirect losses. For example, demolition of bridges that are not properly preserved around the foot structure 
can also cause indirect effects such as loss of life, public and private property damage, and traffic disruption. In the studies carried out, it is seen that the causes of damage in the bridges that are severely damaged or destroyed are mostly due to the pitting around the pile. Damage to structures with a piling bearing system that has been designed with the wrong design is possible, especially due to the carving pattern around it and the depth of the scour hole. The scouring mechanism around the structure in the flow environment is an important field of study in the engineering of water structures. To prevent scoring, the hydrodynamics around the obstacle should be understood well around the pile and at the base near the pile. In this study, three different pile systems (e.g. monopile, duo, and trio groups) were examined under the influence of discharge using the computational fluid dynamics method with the help of OpenFOAM solvent. In the studies conducted, the ground shear stress values around the buildings were calculated and the stone sizes that could be used as a protection structure were calculated.

Keywords: Scour, scour protection, OpenFOAM, computational fluid dynamics

\section{GİRIŞ}

Köprü ayağ1, rüzgar türbini, iskele kazı ̆̆ $1 \mathrm{vb}$. hidrodinamik etkilere maruz kalan yapıların tasarım süreçlerinde dikkat edilmesi gereken önemli kuvvet ve etkiler söz konusundur. Bu kuvvet ve etkilerin hesaplanması ve tasarım süreçlerinin bu hesaplamalar göre gerçekleştirilmesi önemli bir uzmanlık alanıdır. Günümüzde karmaşık dinamik etkilere maruz kalan veya kalması beklenen yapıların tasarım süreçlerinde hesaplamalı akışkanlar dinamiği (HAD) ve bu hesaplamaların doğrulandığı laboratuvar testleri mühendisler için önemli bir araçtır. Köprü, baraj, dalgakıran gibi yatırım maliyetleri yüksek, işletme ömürleri uzun ve karmaşık etkiler altında çalışacak yapıların tasarımların maruz kalacağı dinamik ve statik kuvvetlerin ve yapıların çevresel diğer etkenlere bağlı performansının incelenmesi laboratuvar testlerine göre hesaplamalı akışkanlar dinamiği metodu ile daha ekonomik ve hızlıdır.

Akım ortamı içine inşaa edilen yapıların temellerinde akım karakterinde meydana getirdikleri değişikliğe bağlı olarak oyulma problemi söz konusu olur. Köprü ayakları, rüzgar türbin temelleri, iskele ayakları, boru hatları vb. yapıların ayak ve/veya temel çevresinde ortam akım koşullarına bağlı olarak taban malzemesinde taşınma ve sonucunda oyulma gözlemlenir [1-2]. Bu problemin etkilerinin iyi anlaşılması ve problemlerin çözümü için alternatiflerin değerlendirilmesi önemlidir. Kazık tipi yapılar çevresinde Oyulma problemi daha önce pek çok araştırmacı tarafından çalışılmış önemli bir mühendislik problemidir [3-10].

Köprü ayaklarının oyulma karşı güvenliği farklı yazarlar tarafından hem saha gözlemleri ile hem de deneysel çalışmalarla incelenmiş ve köprü yıkılma olaylarının ana sebeplerinden birisi de ayaklar çevresindeki oyulmanın sebep olduğu anlaşılmıştır [11- 12]. Bir diğer çalışmada da oyulmaya karşı önlemler alınmak adına taban koruma yapısının etkisi incelenmiştir [13]. Farklı testlerle oyulma prosesi ile akım ilişkisinin anlaşılması nümerik ve fiziksel modelleme yöntemleriyle devam etmektedir [14 - 15]. OpenFOAM açık kaynak kodlu bir hidrodinamik modelleme yazılımı olarak engel etrafindaki akım hidrodinamiği ve taban oyulması konularında sıklıkla kullanılmaktadır [16 - 17].

$\mathrm{Bu}$ çalışmada, OpenFOAM aracı kullanılarak, silindir etrafındaki sıvının sıkıştırılamaz, viskoz akışı modellenmiştir. Silindir etrafındaki akışı uygun şekilde yakalamak için çeşitli çözünürlüklerde parametrik ağ modeli geliştirilmiştir ve tabandaki malzemenin hareket edebilmesi için gereken asgari taban kayma gerilmeleri hesaplanmıştır. Elde edilen bu bilgiler kullanılarak oyulma alanları belirlenmiş ve dolgu malzemesi ve miktarı belirlenebilmiştir. Bu çalışma ile birlikte şu sorulara cevap aranmaktadır;

1. Eşdeğer yükü taşıyabilecek kazıklarda tekil veya gruplu kazık sistemlerinin hidrodinamik açıdan en uygunu hangisidir?

2. Kazık sistemlerinde koruma bölgesi sonlu eleman yöntemiyle tespit edilebilir mi? 


\section{MATERYAL VE YÖNTEM}

Çalışmada hesaplamalı akışkanlar dinamiği metdounun uygulanmasında OpenFOAM aracı kullanılmıştır. OpenFOAM; (1) Her türlü problem için yeniden düzenlenebilecek bir yapıya sahiptir. (2) Açık kaynak kodlu ve ücretsiz kullanıma sahiptir. (3) Sonuçların değerlendirilebilmesi ve diğer araçlara aktarılması kolaydır. OpenFOAM aracı ve özel problemler için geliştirilen küçük araçlar veya kodlar sayesinde kolay, hızlı ve anlaşılır sonuçlar üretilebilir. (4) Tüm bu özellikleri sayesinde akademik ve ticari çalışmalarda kabul görmüş bir yazılımdır.

Bütün ortamlarda rahatça çalışılabilmesi adına "docker" aracı yardımıyla sanal bir ortam oluşturulmuştur. Bu sayede simülasyonlar farklı ortamlar ve koşullarda rahatlıkla gerçekleştirilebilmiştir.

Hesaplamaların yapılabilmesi için öncelikle üç boyutlu ve probleme uygun örgü/hesap ağının (mesh domain) üretilmesi gerekmektedir. Hesap ağı üretiminde kullanılan pek çok ücretsiz veya ticari yazılım bulunmaktadır. Bu çalışmada GMSH modülü kullanılmıştır. Bu araç ile hem parametrik modeller elde edilmiş hem de örgü ağı üretimi yapılmıştır. Bütün kazık gurubu modelleri tamamen parametrik (kazık çapına bağlı) olup otomatik bir şekilde oluşturulması için ek kodlara ihtiyaç duyulmuştur.

Çalışmada, OpenFOAM bünyesindeki simpleFoam çözücüsü kullanılmıştır. Bu kararlı durum çözücüsü, sıkıştırılamaz akışkan kabulü ve farklı tip türbülanslı akımları çözebilen bir çözücüdür. SIMPLE (SemiImplicit Method for Pressure-Linked Equations) algoritmasını kullanmaktadır. Brian Spalding ve Suhas Patankar tarafından geliştirilmiş SIMPLE algoritması, hesaplamalı akışkanlar dinamiği simülasyonlarında sıklıkla kullanılan bir algoritmadır [18 - 19]. SIMPLE algoritması ile ilgili literatür tartışmasına ait daha fazla detay Anderson (1995) tarafından tartışılmıştır [20]. Hesaplamalarda kullanılan türbülans modeli olarak k- $\omega$ SST türbülans modeli seçilmiştir. Akışkanın hareketi ise Reynolds Averaged Navier-Stokes (RANS) denklemeleri ile hesaplanmıştır. Bu sıklıkla kullanılan teknik Navier-Stokes denklemlerinin zamana bağlı çözüm ortalamasıdır.

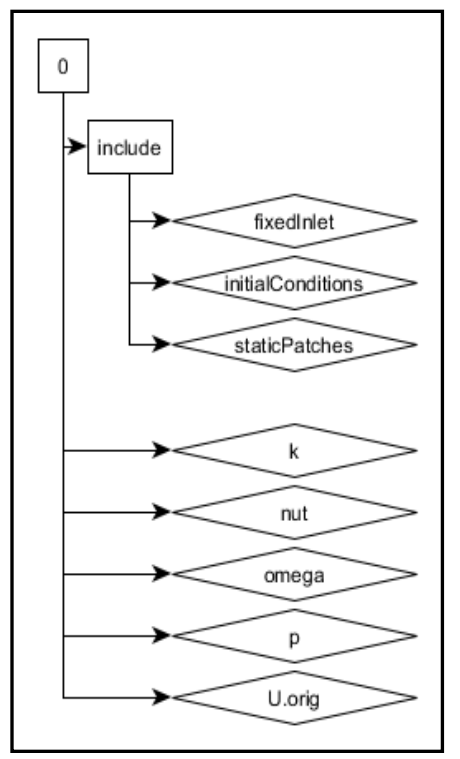

Şekil 1. Model başlangıç koşulları

Akım girişinin yapıldığı sınır koşulu sabit akım değeri olarak tanımlanmıştır. Başka bir dosya olan staticPatches, model başlangıç koşulu gibi sabit olan diğer sınır koşullarını saklamak için oluşturulmuştur. Sağ ve sol sınır koşulu noSlip duvar sınırı olarak ayarlanmıştır. Su yüzeyi ise kayma kontrolü yapılabilmesi adına kayma (slip) sınır koşulu olarak tanımlanmıştır. Başlangıçtaki sınır koşullarını belirtir akım şeması 
Şekil 1'de verilmiştir.Nut dosyası gerçeğe yakın modelleme çalışmaları için önemlidir. Dosyada yüzeylerin pürüzlülük özellikleri belirtilmiştir. Modele ait sınır koşulları Tablo 1'de özetlenmiştir.

Tablo 1. Model sınır koşulları

\begin{tabular}{|l|l|l|l|l|l|}
\hline Model sinır isimleni & $\mathbf{k}$ & nut & omega & $\mathbf{p}$ & $\mathbf{U}$ \\
\hline bottom & kqRWallFunction & nutkRoughWallFunction & omegaWallFunction & zeroGradient & noSlip \\
\hline leftAndRight & kqRWallFunction & calculated & omegaWallFunction & fixedFluxPressure & noSlip \\
\hline outlet & inletOutlet & calculated & inletOutlet & fixedValue & inletOutlet \\
\hline inlet & fixedValue & calculated & fixedValue & zeroGradient & fixedValue \\
\hline pile & kqRWallFunction & nutkWallFunction & omegaWallFunction & zeroGradient & noSlip \\
\hline top & slip & slip & slip & slip & slip \\
\hline
\end{tabular}

Akıntı hızı olarak 0,3 ve $1 \mathrm{~m} / \mathrm{s}$ olmak üzere iki farklı kurgusal sabit değer alınarak tüm testler çalışılmıştır. Taban koşulunda pürüzlülük değeri (ks) 0,0384 alınmış olup 2,5 mm karakteristik kum çapı pürüzlülüğüne eşdeğerdir. Başlangıç koşulu olarak modele tanıtılması gereken diğer bir parametre türbülans kinetik enerjisidir (TKE).

Türbülans kinetik enerjisi denklem 1 yardımıyla hesaplanabilir.

$$
e=\frac{1}{2} \overline{u^{2}}
$$

Denklem 1

Modelleme çalışmasında $1 \mathrm{~m} / \mathrm{s}$ hız değeri için TKE değeri 8,05x10 $10^{-04} \mathrm{~J}$ olarak hesaplanmıştır. Aynı şekilde

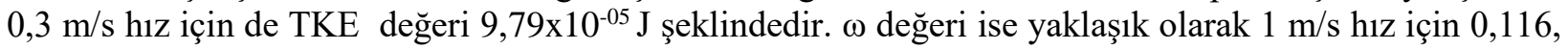
$0,3 \mathrm{~m} / \mathrm{s}$ hız için de 0,04 olarak hesaplanmıştır.

Modelleme çalışmasında 3 farklı kazık sistemi incelenmiştir. Akım doğrultusunda eşdeğer kesite denk gelecek şekilde planlanmış tekli kazık, ikili ve üçlü kazık sistemleri Şekil 2'de sırasıyla a) tekli kazık b) ikili kazık c) üçlü kazık olacak şekilde sunulmuştur. Kazıklar 7 m derinlikteki su ortamı içindedir. Taban rijit taban olarak kabul edilmiş olup oyulma veya birikmeye imkan tanıyacak hareketli taban özellikleri ihmal edilmiş̧ir. Buradaki amaç oyulma mekanizması öncesinde tabanda meydana gelen gerilmelerin incelenmesi olduğundan dolayı bu şekilde harketsiz ve geçirimsiz bir taban kabulü yapılmıştır.

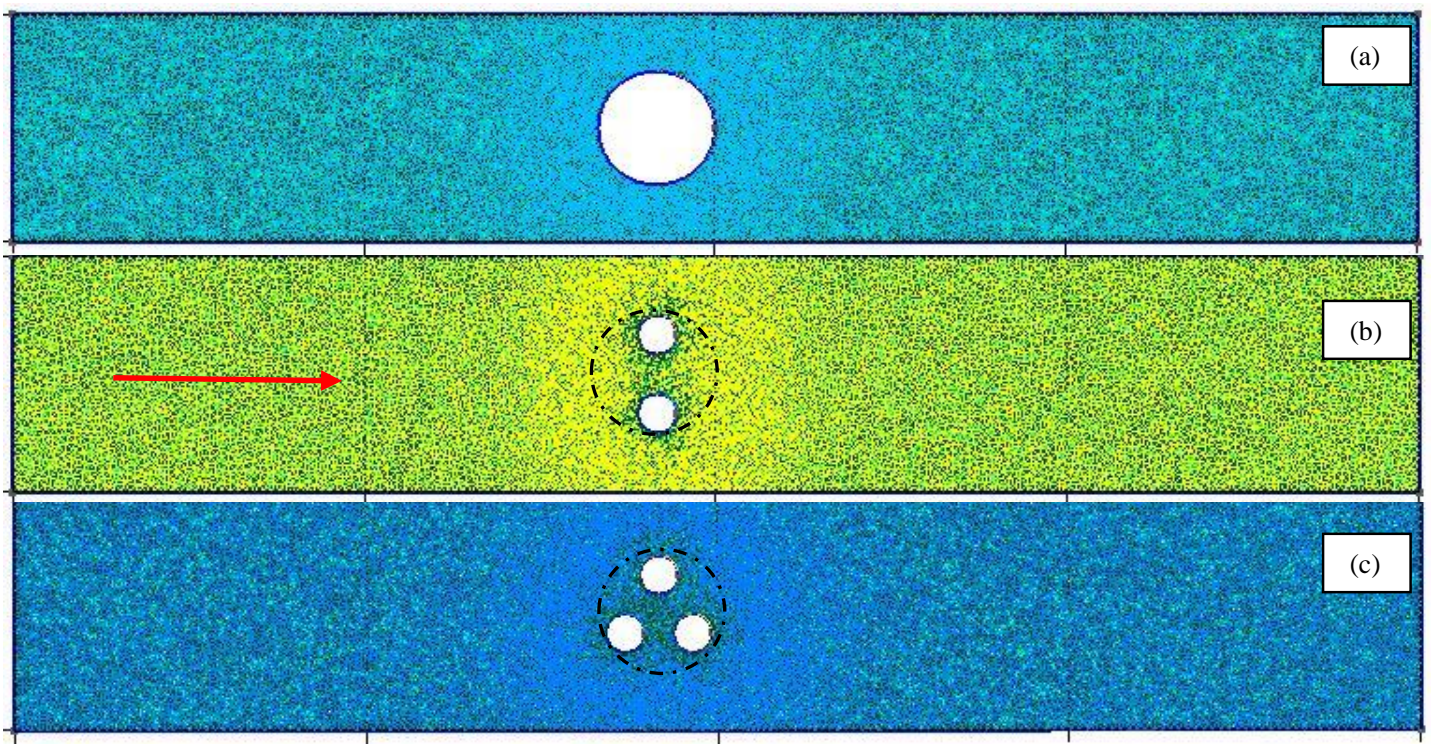


Şekil 2. Modellemede kullanılan a) tekli kazık b) ikili kazık c) üçlü kazık sistemlerinin yerleşim planı

Şekil 2 b) ve c)'de kesikli çizgilerle gösterilen tekli kazığın kesit alanıdır. Kırmızı ok işareti ile şeklin üzerinde gösterildiği gibi akım yönü soldan sağa doğrudur.

Üç farklı kazık sistemi ve iki farklı hız için yapılan hesaplamalar için toplam altı farklı test kurgulanmıştır. Testlerin özeti ve değişim parametreleri Tablo 2'de sunulmaktadır.

Tablo 2. Modelleme Testları

\begin{tabular}{|l|l|l|l|}
\hline Test No & Hiz $(\mathrm{m} / \mathrm{s})$ & Kazık Tipi & Kazık Çap1 $(\mathrm{m})$ \\
\hline Test 1 & 0,3 & Tekil & 7 \\
\hline Test 2 & 0,3 & İkili & 2.33 \\
\hline Test 3 & 0,3 & Üçlü & 2.33 \\
\hline Test 4 & 1 & Tekil & 7 \\
\hline Test 5 & 1 & İkili & 2.33 \\
\hline Test 6 & 1 & Üçlü & 2.33 \\
\hline
\end{tabular}

\section{MODELLEME SONUÇLARI VE TARTIŞMA}

Hesaplamaların sonuçları paraview programı kullanılarak görselleştirilmiştir. Modeller kararlı hal için çözülmüş olup ortalama kinetik enerjisi sabit hale gelene dek iterasyon uygulanmıştır. Her Test için 3.5 (m) derinlikteki Reynolds sayısı ve tabandaki kayma gerilmesi (Pa) dağılımları sırasıyla Şekil 3 - 9 arasında verilmiştir.

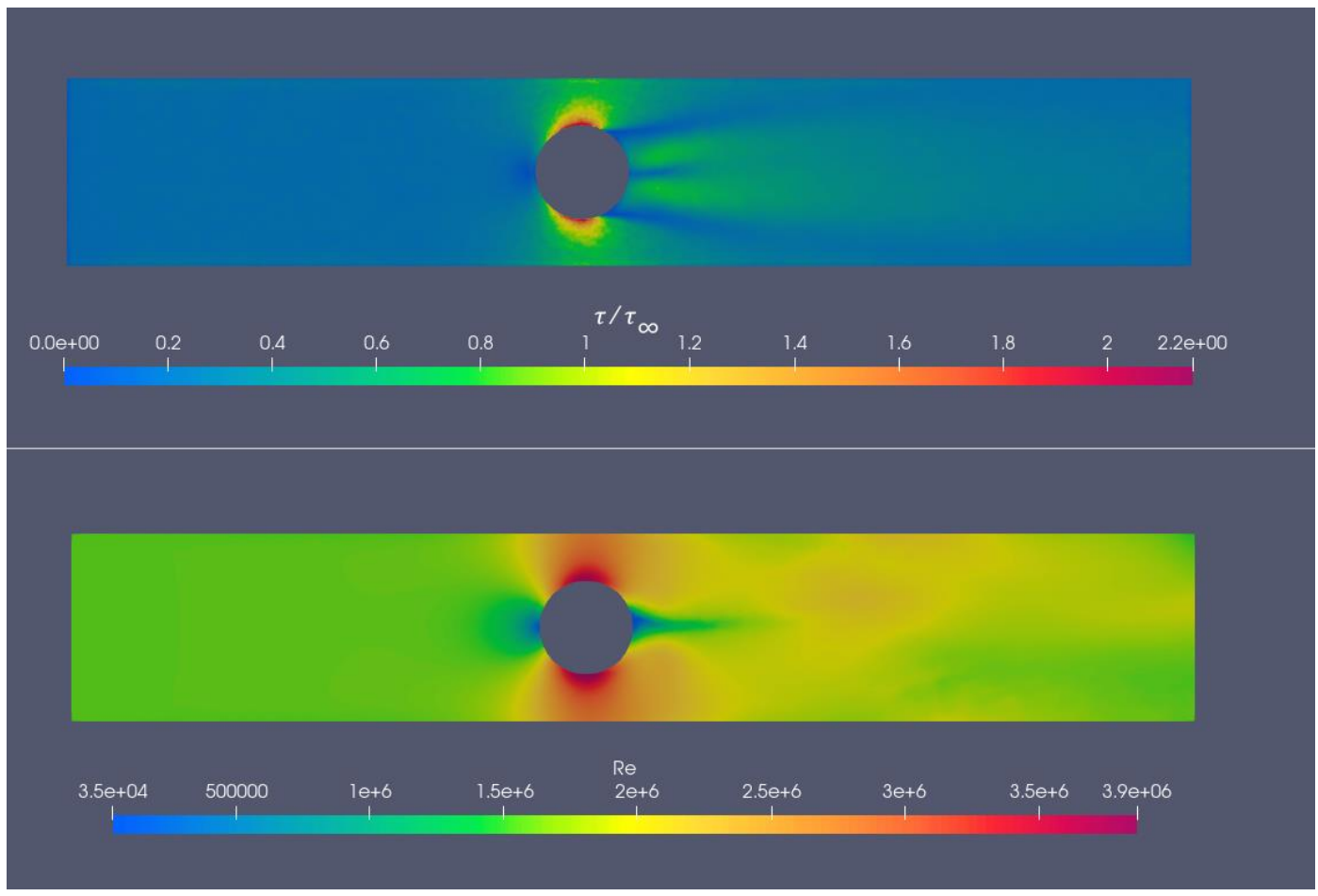

Şekil 3. Test 1 kayma gerilmesi ve Reynolds sayısı dağılımı 


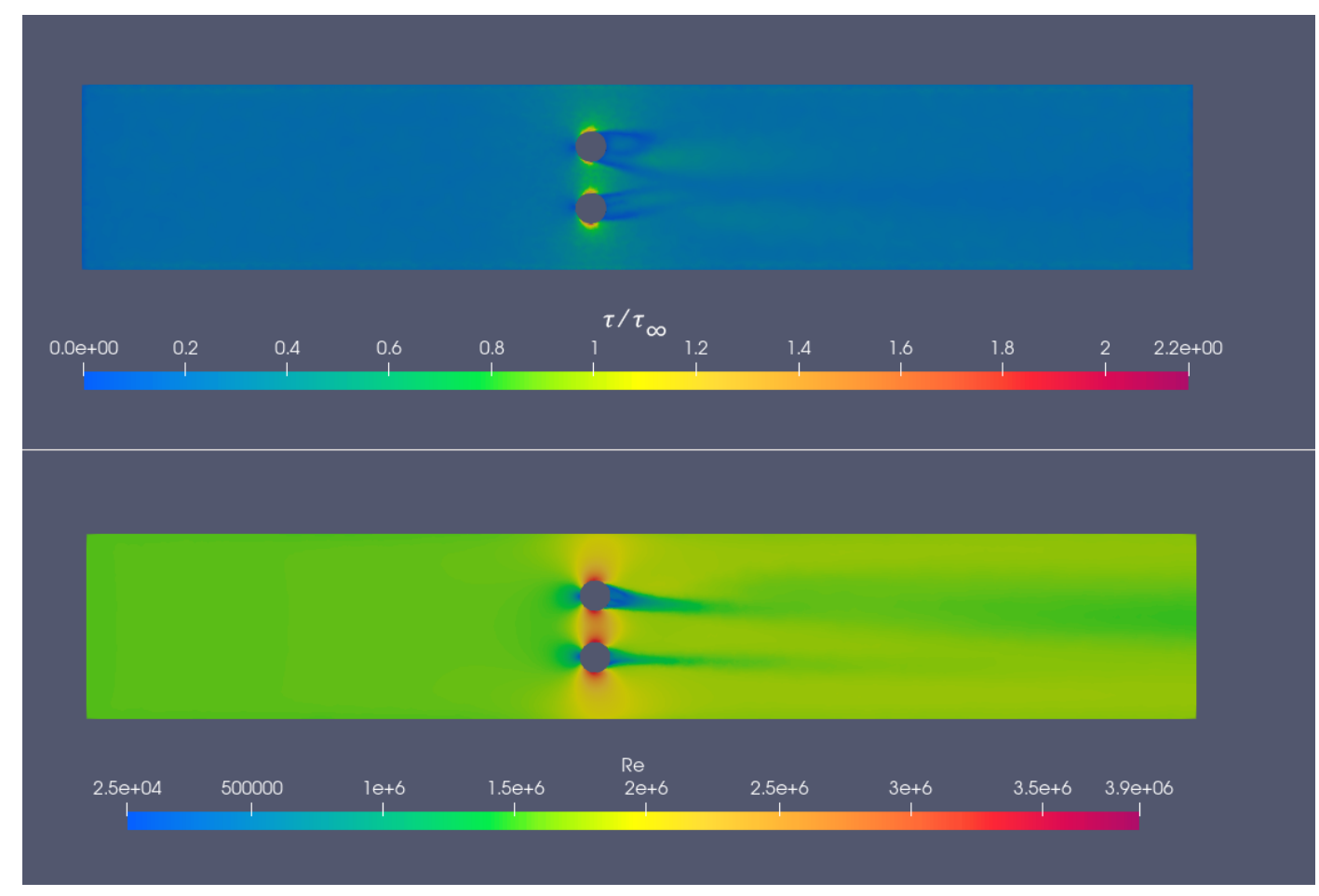

Şekil 4. Test 2 kayma gerilmesi ve Reynolds sayısı dağılımı

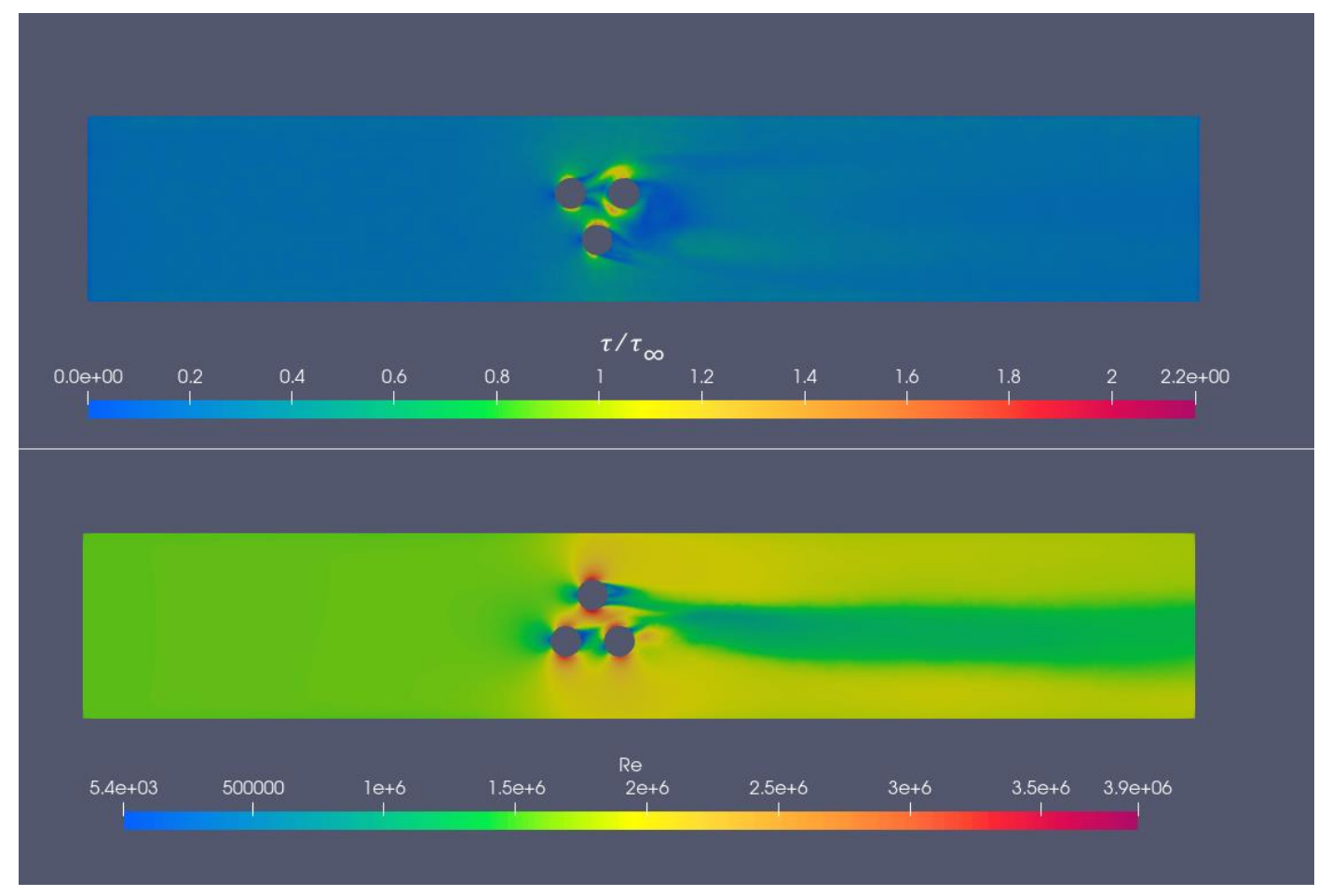

Şekil 5. Test 3 kayma gerilmesi ve Reynolds sayısı dağılımı 


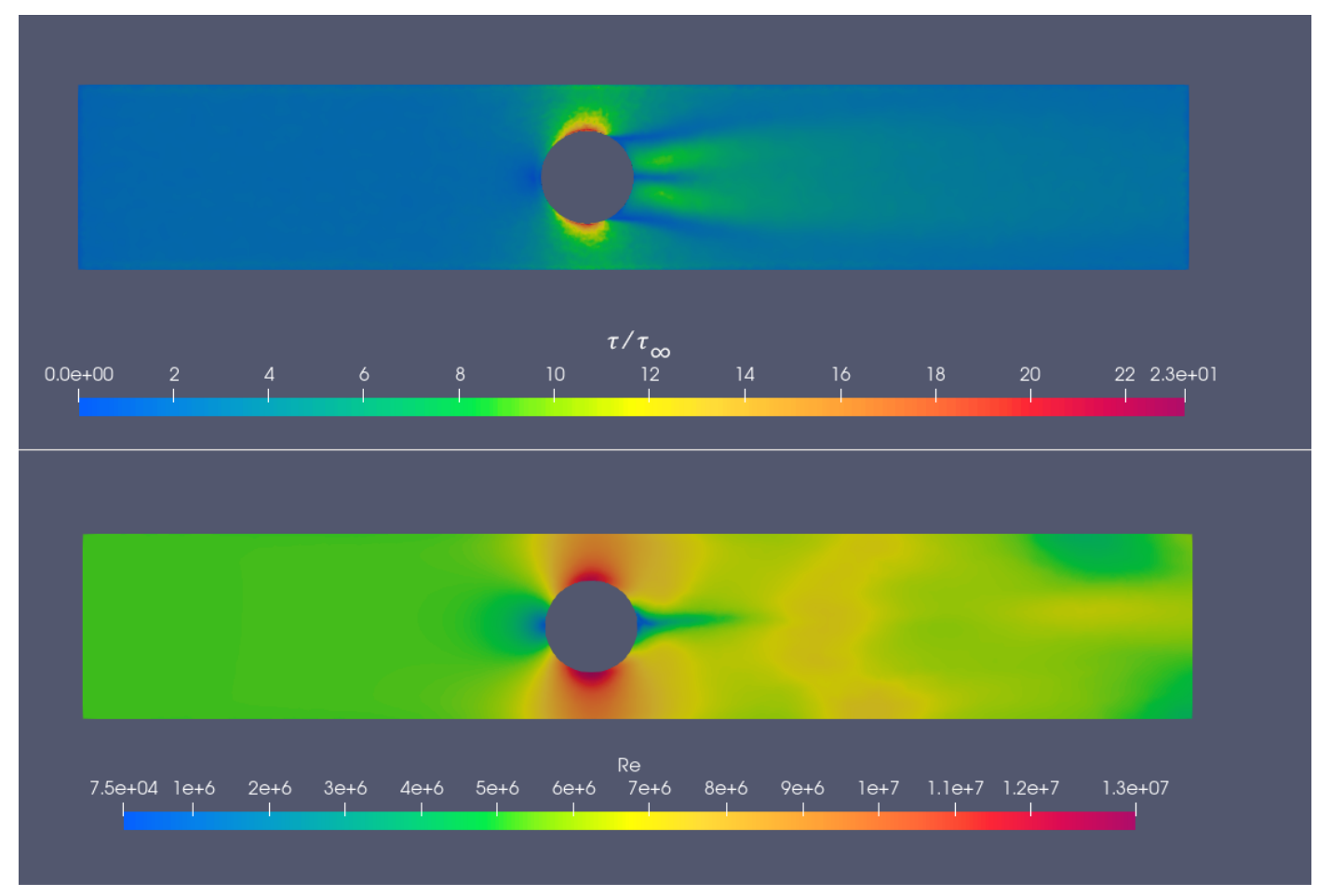

Şekil 6. Test 4 kayma gerilmesi ve Reynolds sayısı dağılımı

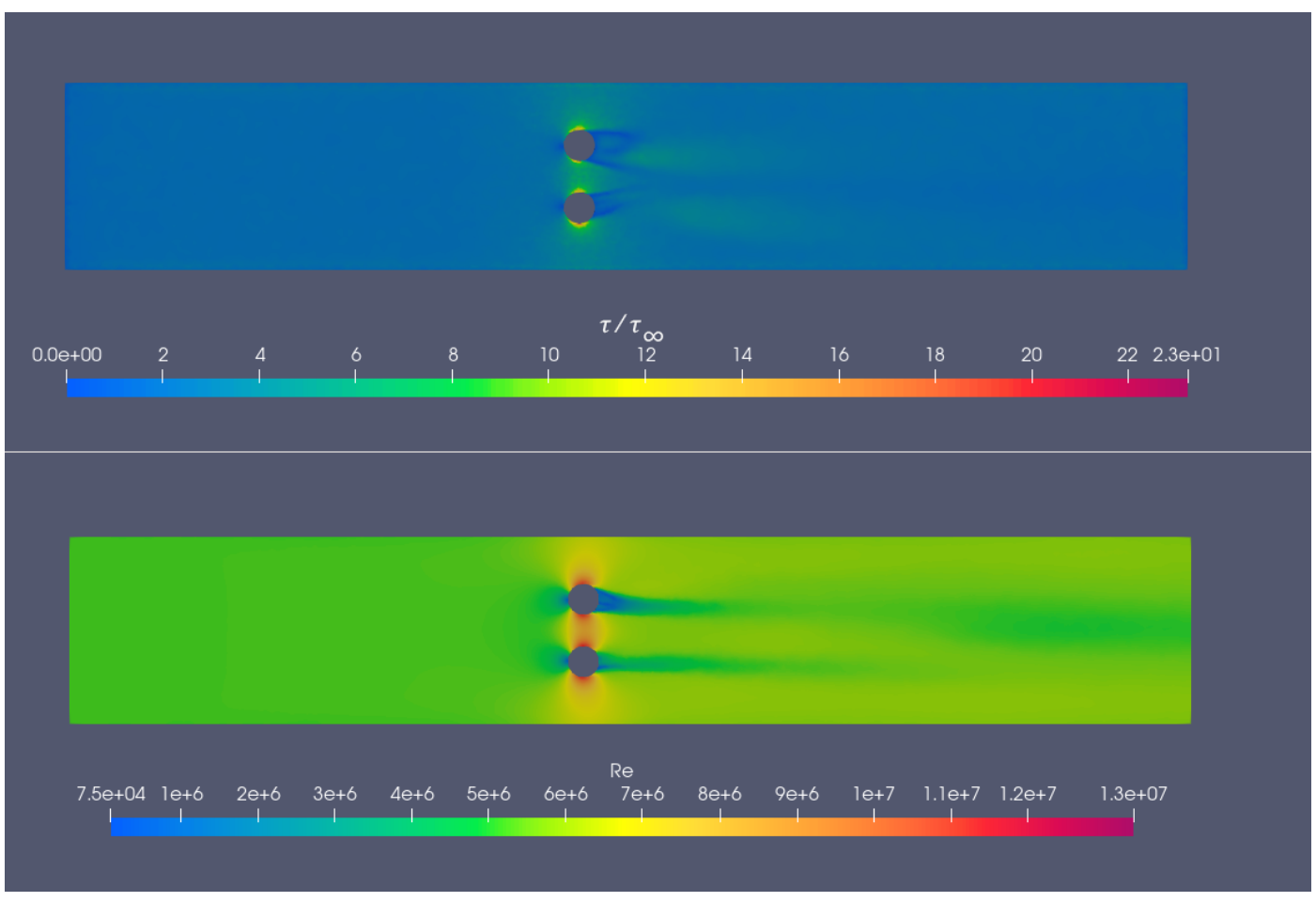

Şekil 7. Test 5 kayma gerilmesi ve Reynolds sayısı dağılımı 


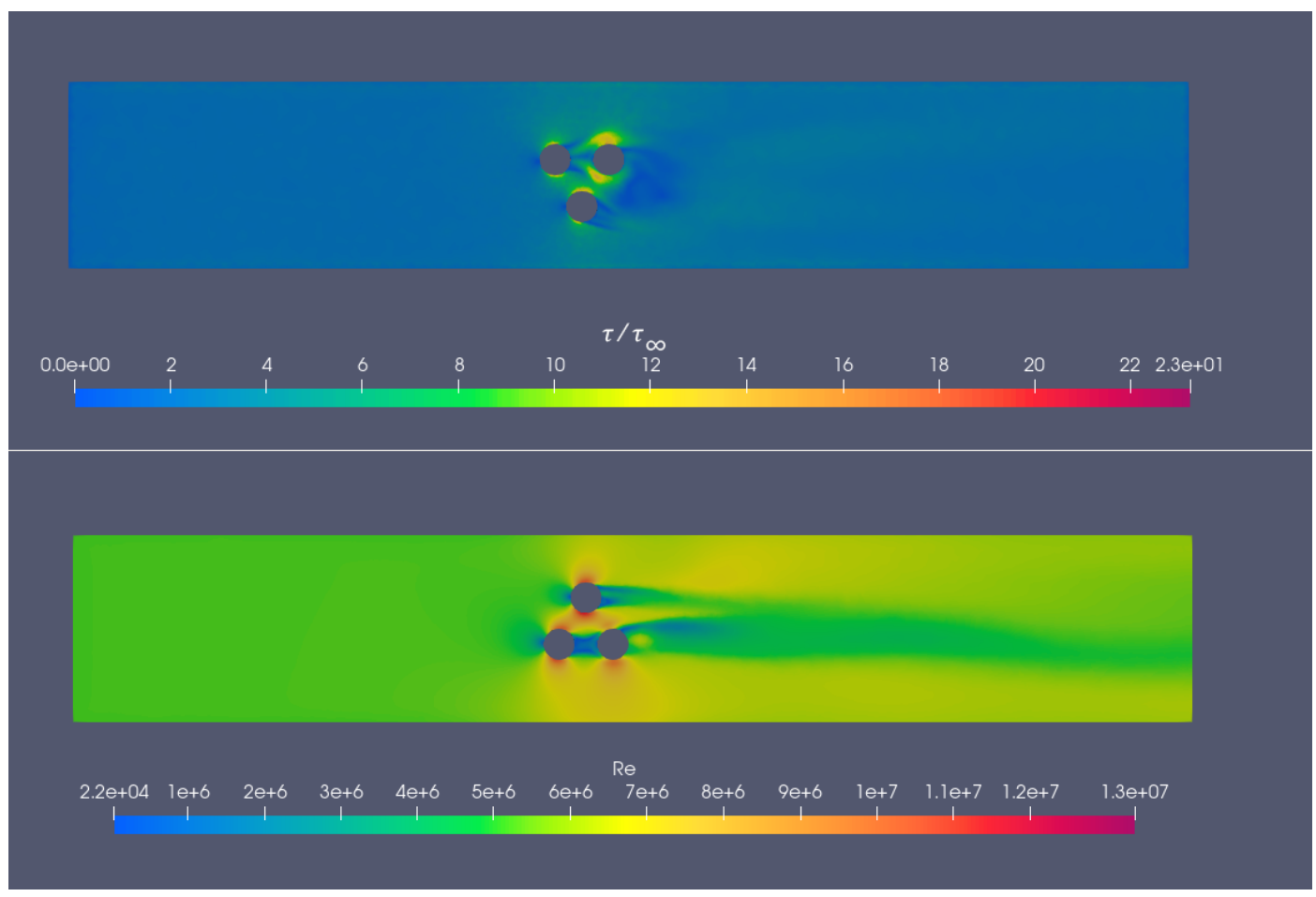

Şekil 8. Test 6 kayma gerilmesi ve Reynolds sayısı dağılımı

Modelleme çalışmaları sonucunda ortalama derinlikte $(3,5 \mathrm{~m})$ elde edilen akım doğrultusundaki Reynolds sayısı dağılım kontürleri ve ve tabandaki taban kayma gerilmesi değerlerine ait dağılım kontürleri üretilerek her bir test için test sırasına uygun olacak şekilde Şekil 3 - Şekil 8 arasında sunulmuştur.

Taban çevresinde görülen kayma gerilmesi dağılımına göre kritik Shield değeri dağılımı hesaplanmış olup 2,5 mm karakteristik tane çapı dikkate alınarak koruma alanı hesaplatılmıştır. Hesaplamalar tabandaki kayma gerilmesi değerinin fonksiyonu olarak pyhton da yazılmış bir kod ile yapılmıştır. Bulunan koruma alanı her bir kazık sistemi için çıkartılmış ve koruma tabakasında kullanılması gereken $\mathrm{d}_{50}$ çap1 Shield parametresi 0,05 'den büyük olacak şekilde kritik Shield değeri hesaplanarak tayin edilmiştir.

Shields parametresinin hesaplanmasında denklem 2 kullanılmaktadır. Denklemde $\theta$ : Shileds parametresini, $\tau$ : taban kayma gerilmesini, $\rho$ değerleri sırasıyla taban malzemesinin ve akışkanın yoğunluğunu, g: yerçekimi ivmesini ve D ise taban malzemesinin karakteristik çapını ifade etmektedir.

$$
\theta=\frac{\tau}{\left(\rho_{S}-\rho\right) \cdot g \cdot D} \quad \text { Denklem } 2
$$

Taban özelliklerine ve meydana gelen kayma gerilmesi değerlerine bağlı olarak hesaplanan Shileds parametresi değeri çalışılan probleme benzer özellikteki akım koşullarında 0,05 ' den büyük ise taban malzemesinin hareket edeceğini göstermektedir. Bu sebeple kritik Shileds değeri 0,05 olacak şekilde kabul edilmiş ve sınır değer olarak hesaplamalarda kullanılmıştır.

Tablo 3. Testlarda hesaplanan en yüksek kayma gerilmesi değeri ve etki alanı

\begin{tabular}{|l|l|l|l|}
\hline Test No & $\tau_{\max }(\mathrm{Pa})$ & $d_{50}(\mathrm{~mm})$ & Koruma alan1 $\left(\mathrm{m}^{2}\right)$ \\
\hline Test 1 & 2,3 & 3 & 30 \\
\hline
\end{tabular}




\begin{tabular}{|l|l|l|l|}
\hline Test 2 & 1,8 & 2,5 & 16 \\
\hline Test 3 & 1,7 & 2,15 & 30 \\
\hline Test 4 & 27 & 34 & 158 \\
\hline Test 5 & 23 & 29 & 123 \\
\hline Test 6 & 19 & 24 & 164 \\
\hline
\end{tabular}

Üçlü kazık grubu ve tekil kazığın tabandaki etki alanı ikili gruptan daha fazladır. Bu durum ikili grubun çevresindeki oyulma bölgesinin diğer iki duruma göre daha sınırlı kalmasına neden olacaktır.

\section{DEĞERLENDİRME VE ÖNERILLER}

Kazık grup sistemleri veya köprü ayağı tipi akım ortamında düzensizlik meydana getiren geçirimsiz yapılar oyulabilir taban üzerine yerleştirildiklerinde mutlaka çevresinde oyulma gerçekleşecektir. Oyulmanın boyutu ve oyulmaya karşı alınacak önlemlerin planlanmasında hesaplamalı akışkanlar dinamiği metodu önemli bir yardımcıdır. Bu konuda açık kaynak kodlu olan OpenFAOM ile bu tür analizlerin yapılması uygundur.

Tekil geniş çaplı bir kazık yerine aynı kesitsel alanı kaplayan grup kazık sistemleri değerlendirildiğinde kazık sayısında hidrodinamik olatak en uygunu ikili grup sistemi olduğu görülmektedir. $\mathrm{Bu}$ durum gerekli koruma maliyetlerininde azalmasına fayda sağlayacaktır. Eşdeğer kesit alansal blokaj sağlayan kazık sistemleri incelendiğinde korunması gereken bölgenin ikili grup sistemi olduğu hesaplanmıştır.

\section{KAYNAKLAR}

[1] B. M. Sumer and J. Fredsoe, Hydrodynamics around cylindrical structures, World Scientific, 1997.

[2] B. M. Sumer and J. Fredsoe, The Mechanics of scour in the marine environment, World Scientific, 2002.

[3] C. Baykal, B. M. Sumer, D. R. Fuhrman, N. G. Jacobsen and J. Fredsoe, "Numerical investigation of flow and scour around a vertical circular cylinder," Phil. Trans. R. Soc. A., vol. 373, 2015.

[4] H. N. Breusers, G. Nicollet and H. W. Shen, "Local scour around cylindrical piers," Journal of Hydraulic Research, vol. 15, no. 3, pp. 211-252, 1977.

[5] M. Ghasemi and S. Soltani-Gerdefaramarzi, "The Scour Bridge Simulation around a Cylindrical Pier Using Flow-3D," Journal of Hydrosciences and Environment, vol. 1, no. 2, pp. 46-54, 2017.

[6] N. G. Jacobsen, G. v. Velzen and J. Fredsoe, "Analysis of pile scour and associated hydrodynamic forces using proper orthogonal decomposition," Perth, Australia, 2014. 
[7] G. Kirkil, G. Constantinescu and R. Ettema, "Coherent structures in the flow field around a circular cylinder with scour hole," Journal of Hydraulic Engineering, vol. 134, pp. 572-587, 2008.

[8] V. Kitsikoudis, O. V. S. Kirca, O. Yagci and M. F. Celik, "Clear-water scour and flow field alteration around an inclined pile," Coastal Engineering, 2017.

[9] V. Kitsikoudis, O. Yagci, O. V. S. Kirca and D. Kellecioglu, "Experimental investigation of channel flow through idealized isolated tree-like vegetation," Environmental Fluid Mech, vol. 16, pp. 1283-1308, 2016.

[10] H. D. Smith and D. L. Foster, "Modeling of Flow Around a Cylinder Over a Scoured Bed," Journal of Waterway, Port, Coastal, and Ocean Engineering, vol. 131, no. 1, pp. 14-24, 2005.

[11] Ö. Köse and A. M. Yanmaz, "Köprü Kenar Ayaklarındaki Oyulma Güvenilirliği," IMO Teknik Dergi, pp. 4919-4934, 2010.

[12] B. W. Melville, Report on local scour at bridge sites (No: 117), Auckland, New Zealand: Univ. of Auckland, School of Engineering, 1975.

[13] Ö. Dursun, E. Gül and T. Sarıcı, "Hidrolik Yapıların Mansabındaki Yerel Oyulma Derinliğine Hücresel Dolgu Sisteminin Etkisinin İncelenmesi," $S u$ Kaynaklarl, vol. 3, no. 2, pp. 61-67, 2018.

[14] J. Meyer, K. Graf and S. Thomas, "Development of an OpenFOAM solver for the simulation of scour around arbitrary offshore foundations," Preprint submitted to Coastal Engineering, 2019.

[15] M. Korkmaz and M. Emiroğlu, "Doksan Derece Kıvrım Açısında Köprü Kenar Ayağı Etrafında Oluşan Oyulmanın İncelenmesi," Fırat Üniversitesi Mühendislik Bilimleri Dergisi, vol. 27, pp. 21-34, 2015.

[16] C. E. Arboleda, M. Wu, P. Troch and V. Stratigaki, "Development and validation of a numerical scour protection around monopiles under currents," in Scour and Erosion IX, Keh-China, 2019.

[17] L. Zhou, NUMERICAL MODELLING OF SCOUR IN STEADY FLOWS, Lyon: Universite de Lyon, 2017.

[18] S. Patankar, Numerical Heat Transfer and Fluid Flow, Taylor \& Francis, 1980.

[19] H. Khawaja, "CFD-DEM Simulation of Minimum Fluidisation Velocity in Two Phase Medium," The International Journal of Multiphysics., vol. 5, no. 2, pp. 89-100, 2011.

[20] J. Anderson, Computational Fluid Dynamics, McGraw-Hill Education, 1995.

[21] V. Kitsikoudis, O. Yagci, V. S. O. Kirca and D. Kellecioglu, "Experimental investigation of channel flow through idealized isolated tree-like vegetation," Environ Fluid Mech, vol. 16, pp. 1283 - 1308, 2016.

[22] S. F. Majd, O. Yagci, O. V. S. Kirca, V. Kitsikoudis and E. Lentsiou, "Flow and turbu- lence around an inclined pile," Rhodes, Greece, 2016.

[23] A. J. Raudkivi and R. Ettema, "Clear water scour at cylindrical piers," Journal of Hydraulic Engineering, vol. 109, no. 3, pp. 338-350, 1983. 
[24] J. E. Richardson and V. G. Panchang, "Three-Dimensional Simulation of ScourInducing Flow at Bridge Piers," Journal of Hydraulic Engineering, vol. 124, no. 5, pp. 530-540, 1998.

[25] A. Roulund, B. M. Sumer, J. Fredsoe and J. Michelsen, "Numerical and experimental investigation of flow and scour around a circular pile," Journal of Fluid Mechanics, vol. 534, pp. 351-401, 2005.

[26] O. Yagci, I. Yildirim, M. F. Celik, V. Kitsikoudis, Z. Duran and O. V. S. Kirca, "Clear water scour around a finite array of cylinders," Applied Ocean Research, vol. 68, p. 114-29, 2017. 